\title{
Evaluation of Germany's Vulnerability Based on Economic Principles and Data Science
}

\author{
Yiliang $\mathrm{Li}^{1}{ }^{1,1 s t}$, Maoguo $\mathrm{Wu}^{2, \mathrm{a}, 2 \mathrm{nd}}$ \\ ${ }^{1}$ SILC Business School Shanghai University Shanghai, China \\ ${ }^{2}$ SILC Business School Shanghai University Shanghai, China
}

\begin{abstract}
Vulnerability refers to the ability of a country or a region to resist internal and external natural factors such as ecological environment, economy, and society during its development. Germany is a country with low overall vulnerability and distinct regional differences, so research on its regional vulnerability can be a representative case for developing countries, as it provides a comprehensive assessment of regional vulnerability via scientific methodology and at the same time proposes rational solutions. The research collects quarterly data of 16 states of Germany from 2000 to 2015. This study describes a series of features of the data and establishes a comprehensive assessment of regional vulnerability including 33 indicators. Combined with the multi-criteria decision analysis method (MCDM), the analytic hierarchy process (AHP) method and the entropy method are applied to calculate the weights. A linear weighted sum method is applied to obtain the regional vulnerability index of Germany. Afterwards, by performing regression tests, this study empirically assess the influencing factors of the regional vulnerability of Germany. Moreover, this study adopts the neural network training model and forecasts the regional vulnerability of Germany of 2016 to 2020 . This study identifies the main factors that influence the regional vulnerability of Germany, and proposes policy implications on the overall regulation to reduce the vulnerability of different regions in Germany accordingly.
\end{abstract}

\section{Introduction}

The concept of vulnerability first appeared in the study of natural disasters. With the expansion and deepening of research methods, the assessment and application of vulnerability are no longer limited to geography. Instead, they have become an important tool in relevant research on sustainability science, which creates great value in many academic fields. Since the current international situation has become increasingly complex, it is not objective to evaluate a country's development and stability unilaterally from the perspective of economic development or military strength. A country's ability in dealing with crises and its resilience to risks should also be considered when formulating national strategies. As a core country of the European Union, Germany is the largest economy in Europe, and the fourth largest economy in the world by nominal GDP. Its stable manufacturing industry and developed financial industry support the economic development of whole country. Meanwhile, with high tax revenue and high welfare, Germany has one of the most developed infrastructures in the world. It ranks the fourth in UN's Human Development Index in 2015. Despite these glorious figures, the regional vulnerability of Germany cannot be neglected. The differences in economic development and the quality of infrastructure of each state result in huge regional differences, thus bringing about a series of potential problems.

Contributing to existing literature on regional vulnerability, this study provides a scientific basis for assessing regional vulnerability and mitigating socioecological problems of Germany, including resource depletion, environmental destruction, as well as optimizing the mode of economic growth. Besides, this study provides macro-level reference for a number of social problems besetting the German government, including the growing refugee crisis and the influx of immigrants. To a certain extent, this study explores the law of national development and sheds light on the sustainable and comprehensive development of Germany. Moreover, this study proposes an assessment method of vulnerability, which can be applied to assess the vulnerability of other countries.

At first, the paper uses min-max normalization to process data and then reduces the dimension by factor analysis. The study establishes a comprehensive assessment system including four layers. Combined with the multi-criteria decision analysis method (MCDM), the weight of each layer can be calculated by the analytic hierarchy process (AHP) method and the entropy method. A linear weighted sum method is also applied to obtain the regional vulnerability index of Germany. Based on the assessment results, this study conducts an exploratory spatial data analysis (ESDA) to show the spatial variation

awumaoguo@shu.edu.cn 
and evolution characteristics of regional vulnerability. In addition, this study also presents an empirical analysis on influencing factors of regional vulnerability of Germany. By performing regression tests, this study empirically tests the relationship between regional vulnerability and 33 influencing factors. Next, this study applies the radial basis function neural network (RBFNN) and simulates ten main factors that influence regional vulnerability. Indicators of each region are imported into RBFNN and trained. At last, practical countermeasure can be proposed to achieve the sustainable development.

\section{Literature Review.}

Sociologists define vulnerability as the ability of a system in dealing with disturbances and recover from events that have adverse effects. Li et al. (2011) defined the concept of urban vulnerability, which provides reference for regional vulnerability. The regional vulnerability defined in this paper is the comprehensive vulnerability of geographical regions based on analysis of spatial variation of Germany, including economic, social and environmental factors. Kochunov (1993) stated that irrational economic structure and mode of economic growth and the negative impacts of human activities such as population pressure and environmental pollution would result in an increase in vulnerability. When vulnerability reaches a certain level, a country/region would become vulnerable.

Fang and Wang (2015) argued that several economic factors, including GDP, tax revenue, R\&D expenditure $(\%$ of GDP) etc., influence vulnerability. Economic development is the material basis of a country/region, so economic factors certainly have a great impact on vulnerability. Therefore, irrational economic structure or low economic efficiency could result in an increase in vulnerability. Fang et al. (2007) also emphasized the impact of economic entities, including industry and capital, on society, which indirectly reflected the possible impact of economic factors on regional vulnerability. Social factors must be taken into account as well. Wang (2014) analyzed a series of social indicators which influence vulnerability, such as road area per capita, disposable income per capita, number of college students per 10,000 people, proportion of science and technology expenditure to local fiscal expenditure etc.. These social factors have potential impact on social vulnerability in terms of social services, social progress, and social life. Fang et al. (2014) illustrated the importance of social vulnerability and the criteria for social vulnerability by the example of Daqing in the overall assessment of urban vulnerability, claiming that social factors including population size, social environment, and infrastructure could have different impacts on social vulnerability. Environmental vulnerability is a force to be reckoned with. Fang et al. (2014) stated that urban ecology is the carrier of human activities, which directly affect the scope of social activities, thus affecting social production. Meanwhile, ecological environment is a link between decomposing and absorbing waste from human development activities, of which the degradation would directly lead to imbalance of human life and the aggravation of natural disasters. Thus, environmental factors have a significant effect on comprehensive vulnerability.

Previous research provides a mature indicator framework for assessing the vulnerability of a target system, including various influencing factors. However, when studying urban/regional vulnerability, there are limitations in weighting the index system in previous research. The analytic hierarchy process (AHP) method and the entropy method are two major methods to calculate the weights of indicators of vulnerability, whereas most previous research only utilizes one of the two methods. Simply using the AHP method would lead to excessive subjectivity, while only using the entropy method could result in a non-prominent focus of subsystems or not considering the actual characteristics of the study object. In addition, linear regression has been frequently used when forecasting vulnerability in existing literature. However, vulnerability is an organic coupling of various factors. It is not appropriate to simulate variable relationships only using linear regression method. Therefore, this study attempts to solve the above mentioned problems by establishing a comprehensive framework for assessment of Germany's regional vulnerability, including 33 measurement indicators from the aspects of economy, society, and environment. The combined AHP-entropy method is applied to calculate weights of the indicator system. This study uses the AHP method to obtain initial weights which are highly subjective. The entropy method, which is more objective in weighing, is used for weight correction to ensure that all indicators are weighted more accurately, thus obtaining more accurate vulnerability index. Furthermore, this study forecasts the regional vulnerability index of Germany using the neural network training model.

\section{Comprehensive Assesment Regional Vulnerability of Germany}

This study collects 33 specific indicators of 16 states of Germany from 2000 to 2015 in the aspects of economy, society, and environment, and establishes a comprehensive assessment system to calculate vulnerability index. The 33 indicators are:

GDP, Tax revenue, Fixed asset investment, Percentage added to GDP by the second sector, Percentage added to GDP by the third sector, The ratio of the actual utilization of foreign capital, Electricity consumption per unit of GDP, Water consumption per unit of GDP, Energy consumption per unit of GDP, R\&D expenditure ( $\%$ of GDP), The number of R\&D personnel, Total retail sales of consumer goods, Average floor area per capita, Passenger volume, Road area per capital, Freight volume, Post and telecommunications business volume, The number of hospitals' beds per 10,000 population, The number of buses per 1,000 population, Fiscal expenditure on science and technology electricity, The number of university graduates per 100 population, The number of patent applications per million population, Built-up areas, Urban population ( $\%$ of total), Population density, Industrial waste gas emissions, Industrial solid waste emissions, 
Industrial waste water emissions, Environmental protection related sales, Built-up area of green coverage, The number of wastewater treatment plants.

\subsection{Factor Analysis and Correlation Test}

It is not appropriate to compare the values of different indicators directly with each other due to great differences between them. All the indicators must be normalized first so values measured on different scales can be adjusted to a notionally common scale. This study uses the min-max normalization method to process all the data. Initially, these indicators are divided into two separate groups: positive indicators and negative indicators. If the indicator is in positive direction, the larger the value of the indicator, the larger the vulnerability is. The formula is given as (1):

$$
\mathrm{x}_{\mathrm{i}}=\frac{\mathrm{x}-\mathrm{x}_{\min }}{\mathrm{x}_{\max }-\mathrm{x}_{\min }}
$$

If the indicator is in negative direction, the larger the value of the indicator, the smaller the vulnerability is. The formula is given as (2):

$$
\mathrm{x}_{\mathrm{i}}=\frac{\mathrm{x}_{\max }-\mathrm{x}}{\mathrm{x}_{\max }-\mathrm{x}_{\min }}
$$

Where $x_{i}$ is the normalized value, $x_{\max }$ is the maximum value of the indicator, $x_{\min }$ is the minimum value of the indicator, $x$ is the original value.

Since all the indicator data in this paper is panel data and measured variables are of high complexity, factor analysis has to be adopted to reduce the dimension of the data and classify the variables. The formula is given as (3):

$$
\begin{gathered}
\mathrm{x}_{1}=a_{11} F_{1}+a_{12} F_{2}+\cdots+a_{1 m} F_{m}+e_{1} \\
x_{2}=a_{21} F_{1}+a_{22} F_{2}+\cdots+a_{2 m} F_{m}+e_{2} \\
\cdots \\
\mathrm{x}_{\mathrm{p}}=a_{\mathrm{n} 1} F_{1}+a_{n 2} F_{2}+\cdots+a_{n m} F_{m}+e_{n}
\end{gathered}
$$

Where $\mathrm{x}_{1} \ldots \mathrm{x}_{\mathrm{n}}$ represent measured variables from the $\mathrm{i}^{\text {th }}$ to the $\mathrm{j}^{\text {th }} \cdot \mathrm{F}_{1} \ldots \mathrm{F}_{\mathrm{m}}$ represent common factors from the $\mathrm{j}^{\text {th }}$ to the $\mathrm{m}^{\text {th }} . \quad a_{11} \ldots a_{n m}$ represent the factor loading of $\mathrm{F}_{\mathrm{j}}$ for the $\mathrm{i}^{\text {th }}$ measured variable, which are also called correlation coefficient $\beta_{i j}$ between $x_{i}$ and $F_{j}$, implying a significant causal relationship between $\mathrm{x}_{\mathrm{i}}$ and the factor $F_{j}$.

By KMO and Bartlett's Test, the KMO value is $0.875>0.5$ and the chi-square value of Bartlett's Test is statistically significant, indicating that the factor analysis is useful with the data. The result shows that 33 indicators are classified into 12 categories on the basis of common factors, and the results are basically in accordance with those of the previously defined framework for the indicators of Germany's regional vulnerability, indicating that the previous classification of 33 indicators is reasonable. By the Kolmogorov-Smirnov Test (K-S Test), the result shows that all the variables are not normally distributed at the significance level of 0.05. By Levene's test, most of the p-values are less than 0.05 , thus accepting the null hypothesis, and the assumption of homogeneity of variance is correct.

\subsection{Establishing the Indicator System}

With the result of factor analysis, the vulnerability of 16 states of Germany from 2000 to 2015 has been analyzed and a four layered indicator evaluation system is established, including the goal layer, the constraint layer, the criteria layer and the indicator layer. The goal layer is Germany's Regional Vulnerability Index (GVI), which this paper attempts to study. The constraint layer subdivides the goal layer into Economic Vulnerability Index (ECVI), Social Vulnerability Index (SVI), and Environmental Vulnerability Index (ENVI). Refining constraint layer, the criteria layer could be established. Economic vulnerability is subdivided into economic scale, economic structure, economic innovation and economic efficiency. Social vulnerability is subdivided into social life, social service and social development. Environmental vulnerability is subdivided into human pressure, pollution pressure and response and solution. Finally, the criteria layer is broken down into the indicator layer, which is a comprehensive indicator measurement including 33 basic statistical indicators, providing a research basis for this paper.

Although there are a lot of indicators in the measurement system of German's regional vulnerability, there are fewer indicators in the constraint layer. It is not difficult to evaluate the significance of indicators of the constraint layer and the ranking method could be applied to determine the weights. To weight the indicators of the criteria layer, the AHP method is used to obtain the initial weights, and the entropy method is used to correct the difference caused by the subjectivity of the AHP method.

AHP is a method for subjective analysis combining quantitative and qualitative approaches, which could deal with multilayer problems that are difficult to be quantified. Based on subjective judgment of humans, indicators and the differences between those indicators are quantified, thus eliminating the influence of the human thinking process.

The judgement matrix is constructed by AHP, and the maximum eigenvalue and the corresponding eigenvectors are calculated. Also, consistency test is performed. Finally, weighting values of the criteria layer are obtained. Drawing a comparison between the weighting values and the mean random consistency index (RI), the results are displayed in table 1:

Table1. Test on the average random consistency index

\begin{tabular}{|c|c|c|c|}
\hline & ECVI & SOVI & ENVI \\
\hline RI & 0.89 & 0.52 & 0.52 \\
\hline $\begin{array}{c}\text { Consistency } \\
\text { Index(CI) }\end{array}$ & 0.076 & 0.019 & 0.027 \\
\hline $\begin{array}{c}\text { Consistency } \\
\text { Ratios(CR) }\end{array}$ & 0.085 & 0.037 & 0.051 \\
\hline
\end{tabular}

Since consistency ratios (CR) of the three criteria are less than 0.1 , the judgement matrix has the satisfying consistency, and the weighting result of the AHP should be accepted. The entropy method is an objective weighting method. The use of the entropy method could eliminate the uncertainty of the result of a subjective weighting method. Using entropy weights to correct subjective weights, the formula is given as (4): 


$$
\mathrm{W}_{\mathrm{i}}=\frac{\omega_{(j-A H P) \omega_{i}}}{\sum_{j=1}^{n} \omega_{(j-A H P) \omega_{j}}}
$$

Where $\omega_{j}$ is the weights obtained from the AHP method, $\omega_{(j-A H P)}$ is the weights obtained from the entropy method. The formula to compute entropy weights is given as (5):

$$
\omega_{\mathrm{j}}=\frac{1-e_{j}}{\sum_{j=1}^{n}\left(1-e_{j}\right)}
$$

Where $e_{j}$ is the information entropy of the $j^{\text {th }}$ indicator, and its formula is given as (6):

$$
\mathrm{e}_{\mathrm{j}}=-\frac{1}{\ln \mathrm{m}} \sum_{i=1}^{m}\left(\frac{r_{i j}}{\sum_{i=1}^{m} r_{i j}} \cdot \ln \frac{r_{i j}}{\sum_{i=1}^{m} r_{i j}}\right)
$$

The ultimate indicator system and the weights of

\begin{tabular}{|c|c|c|}
\hline \multicolumn{3}{|c|}{ Regional Vulnerability } \\
\hline Goal layer & $\begin{array}{c}\text { Constraint } \\
\text { layer(Weighting) }\end{array}$ & $\begin{array}{c}\text { Criteria } \\
\text { layer(Weighting) }\end{array}$ \\
\hline \multirow{10}{*}{$\begin{array}{l}\text { Germany's } \\
\text { Regional } \\
\text { Vulnerability } \\
\text { Index }\end{array}$} & \multirow{4}{*}{$\begin{array}{l}\text { Economic } \\
\text { Vulnerability } \\
\text { Index } \\
(0.30)\end{array}$} & $\begin{array}{l}\text { Economic Scale } \\
\text { Index }(0.5775)\end{array}$ \\
\hline & & $\begin{array}{c}\text { Economic } \\
\text { Efficiency Index } \\
(0.2892)\end{array}$ \\
\hline & & $\begin{array}{c}\text { Economic } \\
\text { Innovation Index } \\
(0.0371) \\
\end{array}$ \\
\hline & & $\begin{array}{c}\text { Economic } \\
\text { Structure Index } \\
(0.0962)\end{array}$ \\
\hline & \multirow{3}{*}{$\begin{array}{c}\text { Social } \\
\text { Vulnerability } \\
\text { Index } \\
(0.30)\end{array}$} & $\begin{array}{c}\text { Social Life Index } \\
(0.1591)\end{array}$ \\
\hline & & $\begin{array}{l}\text { Social Service } \\
\text { Index }(0.3121)\end{array}$ \\
\hline & & $\begin{array}{c}\text { Social } \\
\text { Development } \\
\text { Index }(0.5288) \\
\end{array}$ \\
\hline & \multirow{3}{*}{$\begin{array}{l}\text { Environmental } \\
\text { Vulnerability } \\
\text { Index } \\
(0.40)\end{array}$} & $\begin{array}{c}\text { Human Pressure } \\
\text { Index }(0.2237) \\
\end{array}$ \\
\hline & & $\begin{array}{c}\text { Pollution } \\
\text { Pressure Index } \\
(0.5386)\end{array}$ \\
\hline & & $\begin{array}{c}\text { Response and } \\
\text { Solution Index } \\
(0.2377)\end{array}$ \\
\hline
\end{tabular}
indicators are showed in table 2 as follows:

Table2. Measurement Indicators System for Germany's

\subsection{The Comprehensive Measurement Indicators}

Multi-Criteria Decision Making (MCDM) is adopted to compute Germany Vulnerability index (GVI). The analysis procedure could be summarized as four steps: establishing an evaluation system of indicators, scoring indicators, weighting indicators, determining decision rules.

Based on the indicator data in the criteria layer, the index for sub factors of Germany's regional vulnerability $\left(\mathrm{GVI}_{\mathrm{e}}\right)$ could be computed. The formula is given as (7):

$$
\mathrm{GVI}_{\mathrm{e}}=\frac{\sum_{\mathrm{i}=1}^{\mathrm{m}} X_{i}}{m}
$$

Where $X_{i}$ are the normalized values of the data from the indicator layer, $\mathrm{m}$ is the number of indicators of every criteria. $\mathrm{GVI}_{\mathrm{e}}$ contains all 10 Germany's regional indexes.
Based on 10 criteria indicators in the criteria layer, the index for subsystems of Germany's regional vulnerability $\mathrm{GVI}_{\mathrm{S}}$ could be computed. The formula is given as (8):

$$
\mathrm{GVI}_{\mathrm{s}}=\sum_{\mathrm{i}=1}^{\mathrm{n}}\left(G V I_{e}\right)_{i} W_{i}
$$

Where $\mathrm{n}$ is the number of the indicators of the criteria layer, $\left(\mathrm{GVI}_{\mathrm{e}}\right)_{i}$ is the index value of sub factors of Germany's regional vulnerability, $W_{i}$ is the weight of indicator of criteria layer. $\mathrm{GVI}_{\mathrm{s}}$ contains three indexes from constraint layer. Since Economic Scale Index (ESI), Economic Structure Index (ESTI), Economic Efficiency Index (EEI), Economic Innovation Index (EII), Social Life Index (SLI), Social Service Index (SSI), Social Development Index (SDI) and Response and Solution Index (RSI) are all in negative direction, of which the value should be calculated as ' 1 - Specific Index'.

Once a comprehensive indicator system and weights of indicators of the criteria and constraint layer have been obtained, Germany's Regional Vulnerability Index (GVI) could be computed using the linear weighted sum method. The formula is given as (9):

$$
\mathrm{GVI}=\sum_{\mathrm{i}=1}^{\mathrm{c}}\left(G V I_{s}\right)_{i} K_{i}
$$

After Germany's Regional Vulnerability Index (GVI) has been obtained, a vulnerability classification should be carried out. Since the research objects of vulnerability studies are different, there are no unified and systematic criteria to grade vulnerability levels at present. By analyzing the characteristics of the sample data, the numerical range of vulnerability is determined. Using the equidistant grading method, vulnerability is graded into 5 levels. The detail grading of vulnerability is illustrated in table 3 .

\begin{tabular}{|c|c|c|c|c|c|}
\multicolumn{2}{c}{ Table3. } & \multicolumn{2}{c|}{ categories of Vulnerability } \\
\hline \multirow{2}{*}{ Grades } & $\begin{array}{c}\text { Lower } \\
\text { Level }\end{array}$ & $\begin{array}{c}\text { Low } \\
\text { Level }\end{array}$ & $\begin{array}{c}\text { Modera } \\
\text { te Level }\end{array}$ & $\begin{array}{c}\text { High } \\
\text { Level }\end{array}$ & $\begin{array}{c}\text { Higher } \\
\text { Level }\end{array}$ \\
\hline \multirow{2}{*}{ GVI } & $<0.47$ & $\begin{array}{c}0.48- \\
0.50\end{array}$ & $\begin{array}{c}0.51- \\
0.53\end{array}$ & $\begin{array}{c}0.54- \\
0.56\end{array}$ & $>0.57$ \\
\hline
\end{tabular}

\section{A discussion about Germany's vulnerability}

\subsection{Evolution analysis of Germany's regional vulnerability}

The measurement results of the overall national vulnerability data of Germany from 2000 to 2015 are illustrated in Table 4 below, where Germany's national vulnerability index is the mean of vulnerability index of 16 German states. In 2000 and 2001, Germany has relatively low vulnerability. There is an increase in Germany's national vulnerability from 2002 to 2009 and the country is of moderate vulnerability during this period. From 2010 to 2015, Germany's national vulnerability roughly remains at a low level, whereas in 2012 and 2014, Germany has moderate vulnerability. The average national vulnerability index value of Germany over 16 years (from 2000 to 2015 ) is 0.5088 . 
Table4. Measurement results of Germany's national vulnerability

\begin{tabular}{|c|c|c|c|}
\hline Year & $\begin{array}{c}\text { Vulnerability } \\
\text { Index }\end{array}$ & $\begin{array}{c}\text { Rate of } \\
\text { Change (\%) }\end{array}$ & $\begin{array}{c}\text { Vulnerability } \\
\text { Grades }\end{array}$ \\
\hline $\mathbf{2 0 0 0}$ & 0.5042 & - & Low \\
\hline $\mathbf{2 0 0 1}$ & 0.4952 & -1.83 & Low \\
\hline $\mathbf{2 0 0 2}$ & 0.5150 & 3.85 & Moderate \\
\hline $\mathbf{2 0 0 3}$ & 0.5123 & -0.52 & Moderate \\
\hline $\mathbf{2 0 0 4}$ & 0.5187 & 1.22 & Moderate \\
\hline$\ldots$ & $\ldots$ & $\ldots$ & $\ldots$ \\
\hline $\mathbf{2 0 1 3}$ & 0.5012 & -3.40 & Low \\
\hline $\mathbf{2 0 1 4}$ & 0.5134 & 2.38 & Moderate \\
\hline $\mathbf{2 0 1 5}$ & 0.4906 & -4.65 & Low \\
\hline Mean & 0.5088 & - & Moderate \\
\hline
\end{tabular}

Fig. 1 below shows a fluctuating trend of Germany's national vulnerability index. The fluctuation range of the vulnerability index is narrow and the fluctuation mainly occurs from 2010 to 2015 . There are only small differences between invulnerability grades. Germany's overall national vulnerability is slightly lower than moderate level and is in a relatively good and stable condition.

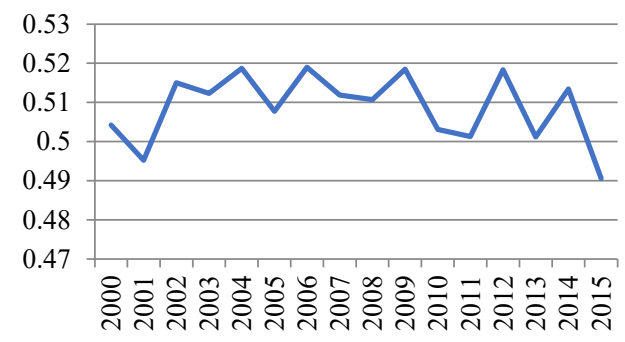

Fig 1. Evolution map of Germany's national vulnerability from

The measurement results of subsystems of Germany's national vulnerability have been further analyzed, which are shown in table 5 below. National subsystem vulnerability is computed using the average value of the data of 16 states.

Table5. Measurement results of Germany's national subsystem vulnerability

\begin{tabular}{|l|c|c|c|}
\hline & ECVI & SOVI & ENVI \\
\hline $\mathbf{2 0 0 0}$ & 0.5236 & 0.5151 & 0.4815 \\
\hline $\mathbf{2 0 0 1}$ & 0.5035 & 0.5009 & 0.4846 \\
\hline $\mathbf{2 0 0 2}$ & 0.5213 & 0.5234 & 0.5039 \\
\hline $\mathbf{2 0 0 3}$ & 0.5032 & 0.5196 & 0.5137 \\
\hline $\mathbf{2 0 0 4}$ & 0.5181 & 0.5308 & 0.5099 \\
\hline $\mathbf{2 0 0 5}$ & 0.5156 & 0.5164 & 0.4951 \\
\hline $\mathbf{2 0 0 6}$ & 0.4930 & 0.5468 & 0.5177 \\
\hline $\mathbf{2 0 0 7}$ & 0.4929 & 0.5220 & 0.5185 \\
\hline $\mathbf{2 0 0 8}$ & 0.5033 & 0.5319 & 0.5004 \\
\hline $\mathbf{2 0 0 9}$ & 0.5328 & 0.5196 & 0.5070 \\
\hline $\mathbf{2 0 1 0}$ & 0.5140 & 0.4915 & 0.5037 \\
\hline $\mathbf{2 0 1 1}$ & 0.5195 & 0.4910 & 0.4954 \\
\hline $\mathbf{2 0 1 2}$ & 0.5146 & 0.5260 & 0.5152 \\
\hline $\mathbf{2 0 1 3}$ & 0.5020 & 0.5086 & 0.4951 \\
\hline $\mathbf{2 0 1 4}$ & 0.5114 & 0.5306 & 0.5021 \\
\hline $\mathbf{2 0 1 5}$ & 0.5113 & 0.4923 & 0.4739 \\
\hline Mean & 0.5113 & 0.5167 & 0.5011 \\
\hline
\end{tabular}

The evolution analysis of Germany's national subsystem vulnerability from 2000 to 2015 is illustrated in Fig. 2 as follows:

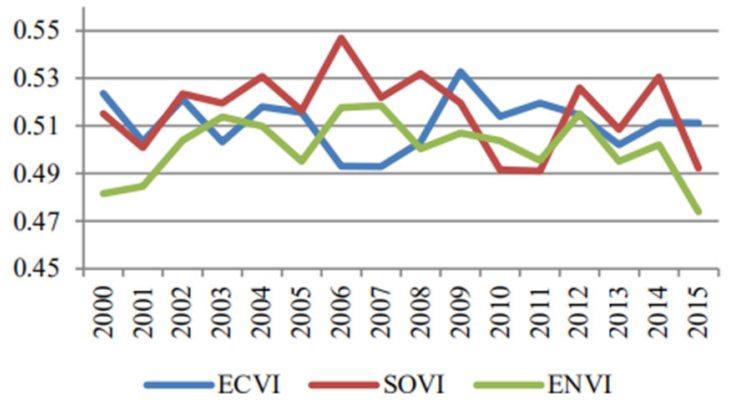

Fig 2. Evolution map of Germany's national subsystem vulnerability

\subsection{The measurement results and evolution of Germany's regional vulnerability}

To further study the characteristics of Germany's regional vulnerability, by comparing and classifying the spatial differentiation of regional vulnerability of Germany and its three subsystems, this paper divides Germany into three regions to conduct analysis, which is illustrated in Fig. 3.

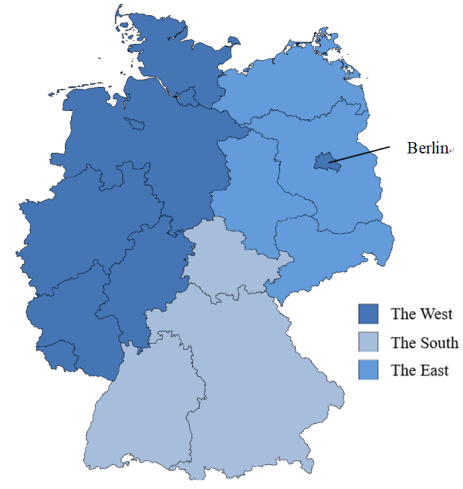

Fig 3. Region division of Germany's regional vulnerability research

Table 6 provides the results of comprehensive measurement of Germany's regional vulnerability. The table shows that the eastern region has the lowest overall vulnerability among three regions, of which the comprehensive vulnerability index value is 0.5049 , followed by the southern region with a comprehensive vulnerability index value of 0.5089 . And the western region has the highest overall vulnerability index value of 0.5105 . In most years, the western region is of moderate vulnerability, whereas the vulnerability of the eastern region fluctuates between a low level and a moderate level. The vulnerability of the southern region is at a moderate level in most years, while reaching an index value of 0.5422 in 2012, which is at a high level. The overall fluctuation range of the vulnerability of the western region is small $(\max 5.99 \%$ ). However, the fluctuation range of the vulnerability of the southern region is large (max $10.55 \%)$. 
Table6. Measurement results of Germany's regional vulnerability

\begin{tabular}{|c|c|c|c|}
\hline & West & East & South \\
\hline $\mathbf{2 0 0 0}$ & 0.5057 & 0.5076 & 0.4952 \\
\hline $\mathbf{2 0 0 1}$ & 0.4883 & 0.5012 & 0.5078 \\
\hline $\mathbf{2 0 0 2}$ & 0.5194 & 0.5147 & 0.5020 \\
\hline $\mathbf{2 0 0 3}$ & 0.5128 & 0.5144 & 0.5082 \\
\hline $\mathbf{2 0 0 4}$ & 0.5305 & 0.4929 & 0.5175 \\
\hline$\ldots$ & $\ldots$ & $\ldots$ & $\ldots$ \\
\hline $\mathbf{2 0 1 3}$ & 0.5029 & 0.5041 & 0.4922 \\
\hline $\mathbf{2 0 1 4}$ & 0.5145 & 0.5178 & 0.5046 \\
\hline $\mathbf{2 0 1 5}$ & 0.4980 & 0.4924 & 0.4663 \\
\hline Mean & 0.5105 & 0.5049 & 0.5089 \\
\hline
\end{tabular}

Based on the index of economic vulnerability, social vulnerability and environmental vulnerability, the measurement results of Germany's regional subsystem vulnerability have been obtained. Part of the measurement values are illustrated in table 7 .

Table7. Part of Measurement results of Germany's regional subsystem vulnerability

\begin{tabular}{|c|c|c|c|c|c|}
\hline & & 2013 & 2014 & 2015 & Mean* \\
\hline \multirow{3}{*}{ West } & $E C V I$ & 0.5082 & 0.5196 & 0.5125 & 0.5112 \\
\hline & SOVI & 0.5149 & 0.5264 & 0.4985 & 0.5183 \\
\hline & $E N V I$ & 0.4899 & 0.5017 & 0.4867 & 0.5042 \\
\hline \multirow{3}{*}{ East } & $E C V I$ & 0.5078 & 0.5199 & 0.5010 & 0.5061 \\
\hline & SOVI & 0.4974 & 0.5175 & 0.4970 & 0.5139 \\
\hline & $E N V I$ & 0.5064 & 0.5163 & 0.4824 & 0.4973 \\
\hline \multirow{3}{*}{ South } & $E C V I$ & 0.4756 & 0.4757 & 0.5212 & 0.5183 \\
\hline & SOVI & 0.5045 & 0.5604 & 0.4676 & 0.5155 \\
\hline & $E N V I$ & 0.4955 & 0.4844 & 0.4241 & 0.4969 \\
\hline
\end{tabular}

*Mean refers to the average value from 2000 to 2015

Table 7 shows that the mean values of subsystem vulnerability index differ slightly from each other. For instance, the western region has the smallest economic vulnerability index value of 0.5112 among three regions, while it has the largest social vulnerability index value of 0.5183 . The environmental vulnerability index of the southern region is the smallest, 0.4969 , which is at a low level.

Furthermore, the value of vulnerability index can be projected into the vector map of Germany. Taking the data of 2015 as an example, the vector maps of SOVI and ENVI are drew as Fig. 4.
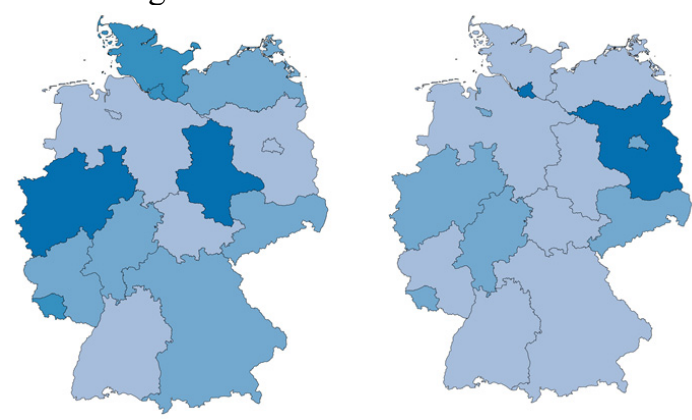

Fig 4. Vector maps of SOVI (left) and ENVI (right)

The color from light blue to dark blue represents the increasing of vulnerability. It is easy to obtain information of every state from the vector map.

\section{Empirical Research on Germany's Regional Vulnerablity}

Since the ultimate vulnerability index is an organic coupling of all the indicators, each indicator or every aspect of indicators has an impact on the overall vulnerability through its impact on subsystem vulnerability. The internal relationship is complex and counterintuitive. Therefore, it is necessary to analyze the factors and degrees of Germany's regional vulnerability by empirical research. In this section, GVI calculated is selected as explanatory variable and previous 33 indicators are explained variables.

\subsection{Preliminary Test}

1)Using unit root test, the result shows that the p-values of the explained variable (Germany's Regional Vulnerability Index) and 33 explanatory variables are less than 0.05 , indicating that there is no unit root. The data of the explained and explanatory variables is considered stable and spurious regression is avoided. Since this paper uses panel data, ordinary least squares (OLS), the fixed effects model or the random effects model could be applied to perform the regression test. Using Breusch-Pagan Lagrange multiplier test, the result shows that OLS is superior to the random effects model. Using F-test, the result shows that OLS has no significant effect and the fixed effects model is superior to OLS. With the Hausman test, the result shows that the fixed effects model is superior to the random effects model. Since the fixed effects model is superior to both OLS and random effects model. This paper finally chooses the fixed effects model. This paper applies the method of Pesaran, Friedman and Fee to conduct the test for cross-sectional correlation. The result shows that the panel data of this paper has crosssectional correlation. This paper also applies the Davidson-Mackinnon test to detect the endogeneity. The result shows that there is no significant endogeneity problem in the data. This paper applies the Modified Wald method to test heteroscedasticity. The result shows that $\mathrm{p}$ value is less than 0.05 and the panel data used in this paper has obvious heteroscedasticity. Therefore, the problem of heteroscedasticity should be taken into account when building a concrete regression model. Thus, this paper chooses the fixed effects model with the correction for heteroscedasticity.

\subsection{Emprirical Results and Robustness Check}

The regression of Germany's regional vulnerability is performed:

$$
\mathrm{GVI}=\alpha+\beta \mathrm{X}+\varepsilon
$$

In the model above, $\alpha$ is the intercept, $\beta$ is the regression coefficient of the model, $\varepsilon$ is the random error. The result of regression analysis is shown in table 8 . Regression (1) applies the fixed effects model with the correction for cross-sectional correlation and heteroscedasticity. Regression (2) applies the Pooled OLS estimation. Regression (3) applies the fixed effects model with the correction for heteroscedasticity. Regression (4) 
applies panel-corrected standard errors (PCSE) model. This paper mainly refers to the result of Regression 1st, which is the fixed effects model with the correction for cross-sectional correlation and heteroscedasticity.

As discussed before, ECVI and SOVI are inversely related with Germany's Regional Vulnerability Index (GVI). Therefore, indicators belonging to those indexes are also inversely related with GVI. Based on the result of Regression (1), the relationship between GVI and 33 explanatory variables can be interpreted.

Table8. Part of Empirical Results and Robustness Check

\begin{tabular}{|c|c|c|c|c|}
\hline \multirow[t]{3}{*}{ Variables } & \multicolumn{4}{|c|}{ Dependent Variable: GVI } \\
\hline & (1) & (2) & (3) & (4) \\
\hline & $\begin{array}{l}\text { Coefficient } \\
\text { (Std. Err.) }\end{array}$ & $\begin{array}{l}\text { Coefficient } \\
\text { (Std. Err.) }\end{array}$ & $\begin{array}{l}\text { Coefficient } \\
\text { (Std. Err.) }\end{array}$ & $\begin{array}{l}\text { Coefficient } \\
\text { (Std. Err.) }\end{array}$ \\
\hline$g d p$ & $\begin{array}{c}0.0562^{* * *} \\
(31.16)\end{array}$ & $\begin{array}{c}0.0565^{* * *} \\
(9.31)\end{array}$ & $\begin{array}{c}0.0562^{* * *} \\
(16.77)\end{array}$ & $\begin{array}{c}0.0565^{* * *} \\
(10.33)\end{array}$ \\
\hline taxrev & $\begin{array}{c}0.0479^{* * *} \\
(6.20) \\
\end{array}$ & $\begin{array}{c}0.0532^{* * *} \\
(9.27) \\
\end{array}$ & $\begin{array}{c}0.0479^{* * *} \\
(10.55)\end{array}$ & $\begin{array}{c}0.0532^{* * *} \\
(7.01)\end{array}$ \\
\hline asset & $\begin{array}{c}0.0559^{* * *} \\
(19.13)\end{array}$ & $\begin{array}{c}0.0573^{* * *} \\
(22.03)\end{array}$ & $\begin{array}{c}0.0559^{* * *} \\
(18.57)\end{array}$ & $\begin{array}{c}0.0573^{* * *} \\
(13.91)\end{array}$ \\
\hline second & $\begin{array}{c}0.00121 \\
(0.20)\end{array}$ & $\begin{array}{c}0.00368 \\
(0.48)\end{array}$ & $\begin{array}{c}0.00121 \\
(0.17) \\
\end{array}$ & $\begin{array}{c}0.00368 \\
(0.64) \\
\end{array}$ \\
\hline third & $\begin{array}{c}0.0111^{*} \\
(1.89)\end{array}$ & $\begin{array}{c}0.0183^{*} \\
(1.98)\end{array}$ & $\begin{array}{c}0.0111^{* * *} \\
(3.43)\end{array}$ & $\begin{array}{c}0.0183^{* * *} \\
(3.80)\end{array}$ \\
\hline foreigninv & $\begin{array}{c}0.0121^{* * *} \\
(4.11)\end{array}$ & $\begin{array}{c}0.0122^{* * *} \\
(3.26)\end{array}$ & $\begin{array}{c}0.0121^{* *} \\
(2.56)\end{array}$ & $\begin{array}{c}0.0122^{* * *} \\
(3.24)\end{array}$ \\
\hline elec & $\begin{array}{c}0.0301^{* * *} \\
(7.24) \\
\end{array}$ & $\begin{array}{c}0.0332^{* * *} \\
(8.77) \\
\end{array}$ & $\begin{array}{c}0.0301^{* * *} \\
(12.30)\end{array}$ & $\begin{array}{c}0.0332^{* * *} \\
(5.78) \\
\end{array}$ \\
\hline water & $\begin{array}{c}0.0275^{* * *} \\
(10.18)\end{array}$ & $\begin{array}{c}0.0283^{* * *} \\
(4.57)\end{array}$ & $\begin{array}{c}0.0275^{* * *} \\
(8.20)\end{array}$ & $\begin{array}{c}0.0283^{* * *} \\
(5.98)\end{array}$ \\
\hline ener & $\begin{array}{c}0.0241 * * * \\
(6.53)\end{array}$ & $\begin{array}{c}0.0278^{* * * *} \\
(5.66)\end{array}$ & $\begin{array}{c}0.0241 * * * \\
(6.91)\end{array}$ & $\begin{array}{c}0.0278^{* * *} * \\
(6.15)\end{array}$ \\
\hline$r d g d p$ & $\begin{array}{c}0.000118 \\
(0.03) \\
\end{array}$ & $\begin{array}{c}0.00296 \\
(0.59) \\
\end{array}$ & $\begin{array}{c}0.000118 \\
(0.03) \\
\end{array}$ & $\begin{array}{c}0.00296 \\
(0.86) \\
\end{array}$ \\
\hline$\cdots$ & $\ldots$ & $\ldots$ & $\cdots$ & $\ldots$ \\
\hline pwat & $\begin{array}{c}0.0690 * * * \\
(26.25)\end{array}$ & $\begin{array}{c}0.0704 * * * \\
(13.59) \\
\end{array}$ & $\begin{array}{c}0.0690 * * * \\
(23.50)\end{array}$ & $\begin{array}{c}0.0704 * * * \\
(20.13)\end{array}$ \\
\hline evsale & $\begin{array}{c}0.0285^{* * * *} \\
(15.44)\end{array}$ & $\begin{array}{c}0.0297 * * * \\
(7.54)\end{array}$ & $\begin{array}{c}0.0285^{* * * *} \\
(16.69)\end{array}$ & $\begin{array}{c}0.0297 * * * \\
(7.73)\end{array}$ \\
\hline greenr & $\begin{array}{c}0.0356^{* * * *} \\
(6.95)\end{array}$ & $\begin{array}{c}0.0380^{* * *} \\
(16.60)\end{array}$ & $\begin{array}{c}0.0356^{* * * *} \\
(18.77) \\
\end{array}$ & $\begin{array}{c}0.0380 * * * \\
(11.80)\end{array}$ \\
\hline watplt & $\begin{array}{c}0.0263^{* * *} \\
(7.05)\end{array}$ & $\begin{array}{c}0.0298^{* * *} \\
(8.45)\end{array}$ & $\begin{array}{c}0.0263^{* * *} \\
(6.81)\end{array}$ & $\begin{array}{c}0.0298^{* * *} \\
(9.44) \\
\end{array}$ \\
\hline _cons & $\begin{array}{c}0.0417^{*} \\
(1.92) \\
\end{array}$ & $\begin{array}{l}0.0175 \\
(0.69) \\
\end{array}$ & $\begin{array}{c}0.0417^{* *} \\
(2.85) \\
\end{array}$ & $\begin{array}{l}0.0175 \\
(1.19) \\
\end{array}$ \\
\hline$N$ & 256 & 256 & 256 & 256 \\
\hline
\end{tabular}

\subsection{Prediction}

Based on the quantitative measurement of Germany's regional vulnerability above, this paper conducts simulation on dynamic evolution of Germany's regional vulnerability and establishes a scientific predictive model to make quantitative predictions on Germany's regional vulnerability of 2016 to 2020 . Since this paper sets 33 indicators which are of broad scope and complex relationships, it is impossible to use all the factors in the predictive model. Therefore, to improve the accuracy of the predictive model, this paper extracts the most representative influencing factors to establish the model.

Table9. the List of main variables

\begin{tabular}{|l|l|}
\hline Coefficient & \multicolumn{1}{|c|}{$\beta_{\mathrm{i}} \geq 0.04$} \\
\hline \multirow{3}{*}{ ECVI } & GDP \\
\cline { 2 - 2 } & Tax revenue \\
\cline { 2 - 2 } & Fixed asset investment \\
\hline \multirow{4}{*}{ SOVI } & Fiscal expenditure on education \\
\cline { 2 - 2 } & Fiscal expenditure on science and technology \\
\cline { 2 - 2 } & $\begin{array}{l}\text { The number of university graduates per 100 } \\
\text { population }\end{array}$ \\
\hline
\end{tabular}

\begin{tabular}{|l|l|}
\hline \multirow{2}{*}{ ENVI } & $\begin{array}{l}\text { The number of patent applications per } \\
1000000 \text { population }\end{array}$ \\
\hline & Industrial waste gas emissions \\
\cline { 2 - 2 } & Industrial solid waste emissions \\
\cline { 2 - 2 } & Industrial waste water emissions \\
\hline
\end{tabular}

Since Germany's regional vulnerability is a comprehensive manifestation and organic coupling of economic, social and environmental factors, only considering the linear relationship is not enough sufficient. Indicators are more likely to have non-linear relationships. To improve the comprehensiveness, accuracy and scientificity of the prediction model, this paper uses the Artificial Neural Network training model to simulate and forecast Germany's regional vulnerability.

Radial basis function (RBF) networks typically have three layers: an input layer, a hidden layer and an output layer. This paper uses Gaussian Function which is commonly applied by current research as the radial basis function. The formula is given as (11):

$$
\mathrm{R}\left(\mathrm{x}_{\mathrm{p}}-\mathrm{c}_{\mathrm{i}}\right)=\exp \left(-\frac{1}{2 \sigma^{2}}\right)\left\|\mathrm{x}_{\mathrm{p}}-\mathrm{c}_{\mathrm{i}}\right\|^{2}
$$

Where $\|\ldots\|$ is Euclidean norm, $\mathrm{c}$ is the center of Gaussian function and $\sigma$ is the variance.

Using Gaussian Function, the output of the network is a linear combination of the output of neurons in the hidden layer. The formula is given as (12):

$$
\mathrm{y}_{\mathrm{i}}=\sum_{i=1}^{h} \omega_{i j} \exp \left(-\frac{1}{2 \sigma^{2}}\left\|\mathrm{x}_{\mathrm{p}}-\mathrm{c}_{\mathrm{i}}\right\|^{2}\right)
$$

Where $x_{p}$ is the $p^{\text {th }}$ input sample, $c_{i}$ is the center of hidden-layer nodes, $\omega_{i j}$ is the weight value from the hidden layer to the output layer. The number of hiddenlayer nodes is $\mathrm{h}$ and the number of output nodes is $\mathrm{n} . \mathrm{y}_{\mathrm{i}}$ is the actual output of the $\mathrm{j}^{\text {th }}$ output node of the network input sample.

This paper applies the Radial Basis Function Neural Network (RBFNN) with SPSS to simulate main factors affecting Germany's regional vulnerability which are extracted from the indicator system. Indicators of each region, West, East, and South are loaded into RBFNN and trained. This paper utilizes historical data of ten main factors from 2000 to 2015 as the training set and performs an out-of-sample prediction of the vulnerability of 2016 to 2020 .

Table10. Predicted Values of 2016-2020

\begin{tabular}{|c|c|c|c|c|c|c|}
\hline & & $\mathbf{2 0 1 6}$ & $\mathbf{2 0 1 7}$ & $\mathbf{2 0 1 8}$ & $\mathbf{2 0 1 9}$ & $\mathbf{2 0 2 0}$ \\
\hline \multirow{3}{*}{ West } & $\boldsymbol{E C V I}$ & 0.5124 & 0.4914 & 0.5076 & 0.4995 & 0.4913 \\
\cline { 2 - 7 } & $\boldsymbol{S O V I}$ & 0.5144 & 0.5102 & 0.5163 & 0.5012 & 0.4982 \\
\cline { 2 - 7 } & $\boldsymbol{E N V I}$ & 0.4911 & 0.5008 & 0.4897 & 0.5016 & 0.4860 \\
\hline \multirow{4}{*}{ East } & $\boldsymbol{E C V I}$ & 0.5107 & 0.5188 & 0.5078 & 0.5098 & 0.5011 \\
\cline { 2 - 7 } & $\boldsymbol{S O V I}$ & 0.5105 & 0.5056 & 0.4967 & 0.5068 & 0.4957 \\
\cline { 2 - 7 } & $\boldsymbol{E N V I}$ & 0.4985 & 0.4963 & 0.5065 & 0.5055 & 0.4821 \\
\hline \multirow{3}{*}{ South } & $\boldsymbol{E C V I}$ & 0.5038 & 0.5126 & 0.4951 & 0.4850 & 0.4914 \\
\cline { 2 - 7 } & $\boldsymbol{S O V I}$ & 0.5055 & 0.5174 & 0.5042 & 0.5205 & 0.4873 \\
\cline { 2 - 7 } & $\boldsymbol{E N V I}$ & 0.5150 & 0.5129 & 0.4958 & 0.4849 & 0.4747 \\
\hline
\end{tabular}

\section{Conclusion}

This paper collects the quarterly data of 16 states of Germany from 2000 to 2015 and establishes a 
comprehensive measurement system including 33 indicators. Combined with the Multi-Criteria Decision Analysis Method (MCDM), this paper applies the Analytic Hierarchy Process (AHP) and entropy method and linear weighted sum method to obtain the regional vulnerability index of Germany. This paper also presents an empirical analysis of influencing factors of Germany's regional vulnerability. In addition, this paper forecasts Germany's Vulnerability Index of 2016 to 2020 using the Artificial Neural Network training model and proposes related policy recommendations. The following conclusions can be drawn from the results of regression and prediction:

In the measurement system of 33 indicators, there are ten main factors that affect Germany's regional vulnerability. Therefore, the government should take into careful considerations these ten factors when proposing solutions to vulnerability. The government should promote regional development to increase GDP and tax revenue. The government should also increase investment in science, technology and education and focus on the impact of social progress on the decrease of social vulnerability. Moreover, the government is supposed to control pollution emissions to reduce environmental pressure when developing.

Since there are prominent spatial differentiation characteristics of regional vulnerability in Germany, the government should take into account the different features of different regions when formulating strategies. To be specific, the western region, which is dominated by heavy industry, should focus on controlling environmental vulnerability. The eastern region, where the political center is located and the industrial structure is relatively single, should focus on controlling economic vulnerability. The southern region, where the population pressure is high and the infrastructure is poor compared with other two regions should focus on controlling social vulnerability. Additionally, the German government should also reduce the volatility of vulnerability of different regions to reaches an ideal stable condition.

The result of prediction shows a decreasing trend of Germany's regional vulnerability year by year, but there is still a possibility of rebound or mutation. For example, the overall vulnerability of the western region fluctuates greatly with a relatively high instability, especially after 2013. To reduce uncertainties and achieve balance, the government should control the fluctuation range of vulnerability on the basis of different indicators and different characteristics of different regions.

\section{References}

1. White G F. Natural Hazards. Oxford: Oxford University Press, 1975: 4-18.

2. Li He. Vulnerability of mining cities in Northeast China and its control measures. Areal Research and Development, 2011, 30 (5): 78-83.

3. Yu Xiaohong, Xia Antao, Liu Yingjun. Research of urban vulnerability and its countermeasures. Journal of Hunan City University, 2007, 29(4): 97-98.
4. Kochunov B I. Concepts and classification of fragile ecosystem. Li Guodong, trans. Geography Translation Report, 1993, 12(2): 19-22.

5. German Statistical Bureau, https://www.destatis.de/DE/Startseite.html, 2018

6. Q He, S Mirzaee A comprehensive assessment of urban vulnerability and its spatial differentiation in China, Journal of Geographical Sciences, 2016 , 26 (2) :153-170

7. B Khazai, M Merz, C Schulz, D Borst, An integrated indicator framework for spatial assessment of industrial and social vulnerability to indirect disaster losses, Natural Hazards, 2013 , 67 (2) :145167 